\title{
INTERAÇõES DA TECTÔNICA NO ENSINO DE PROJETO DE ARQUITETURA
}

\author{
TECTONICS INTERACTIONS IN TEACHING ARCHITECTURE DESIGN
}

\author{
(D) Leticia Mattana ${ }^{1}$ \\ (D) João Carlos Souza ${ }^{2}$ \\ (D)Andréa Holz Pfützenreuter ${ }^{3}$ \\ (D)Anna Freitas Portela de Souza \\ Pimenta 4 \\ ${ }^{1}$ Universidade Federal de Santa Catarina, \\ Florianópolis, SC, Brasil, \\ leticia.mattana@ufsc.br \\ 2 Universidade Federal de Santa Catarina, \\ Florianópolis, SC, Brasil, \\ joao.carlos@ufsc.br \\ 3 Universidade Federal de Santa Catarina, \\ Joinville, SC, Brasil, andrea.hp@ufsc.br \\ 4 Universidade Federal de Santa Catarina, \\ Florianópolis, SC, Brasil, \\ anna.pimenta@ufsc.br
}

\begin{abstract}
Resumo
Considerando a interdisciplinaridade proposta nos ateliês de projeto de arquitetura, um dos temas desafiadores para professores e estudantes é a abordagem da tectônica no ensino de projeto arquitetônico. Este trabalho tem como objetivo compreender as necessidades, expectativas e demandas da tectônica em um ateliê de projeto de arquitetura de um curso de Graduação em Arquitetura e Urbanismo, com proposição de solução para a demanda exposta, adotando a abordagem do design thinking. Para a coleta de dados, optou-se pelas técnicas de observação participante, entrevistas dirigidas e aplicação do mapa de empatia, sendo a análise de dados documental, caracterizando uma pesquisa qualitativa. Os resultados demonstram que as três principais demandas da tectônica em ateliê de projeto de arquitetura estão relacionadas aos conteúdos de concepção estrutural, entendimento sobre contenções estruturais e sobre qual a melhor solução técnica para cada projeto. Como contribuição, foi elaborado um protótipo em ambiente de aprendizagem virtual, que contemplou conteúdos sobre os principais temas solicitados pelo público-alvo da pesquisa. A solução incentiva a autonomia e proatividade dos estudantes na busca pelo conhecimento, reduz a competitividade, promove a comunicação e compartilhamento de conhecimentos entre estudantes e professores, minimizando as dificuldades relatadas no ateliê de projeto de arquitetura envolvendo a tectônica.
\end{abstract}

Palavras-chave: Tectônica. Ensino-aprendizagem. Projeto de arquitetura. Design thinking. Ambiente virtual de aprendizagem.

\begin{abstract}
Considering the interdisciplinarity of teaching architecture in a design studio, one of the challenging themes for faculty and students is tectonics in the teaching and learning of architectural design. This study aims to understand the needs, expectations, and demands of tectonics for an architecture design studio of an undergraduate course in Architecture and Urban Design, with a solution proposal to exposed demands, through a design thinking approach. For data collection, we opted for participant observations, guided interviews, and the application of empathy mapping. Analysis of data was documental, characterizing qualitative research. The results demonstrate that structural design, understanding of structural restraints, and judgments on each project's best technical solutions are the three main demands of tectonics in an architectural design studio. As a contribution, a prototype in a virtual learning environment was created, which included content on the research's target audience's main topics. This prototype encourages students' autonomy and proactivity in searching for knowledge, reduces competitiveness, and promotes communication and knowledge sharing between students and teachers, minimizing the difficulties found in an architecture project studio concerning tectonics.
\end{abstract}

Keywords: Tectonics. Teaching and learning. Architectural design. Design thinking. Virtual Learning Environment.

Editor Responsável:

Rafael Urano Frajndlich (D)

How to cite this article:

MATTANA, L.; SOUZA, J. C.; PFÜTZENREUTER, A.H.; PIMENTA, A. F. P. de S. Interações da tectônica no ensino de projeto de arquitetura. PARC Pesquisa em Arquitetura e Construção, Campinas, SP, v. 12, p. e021008, 2021. DOI: http://dx.doi.org/10.20396/parc.v12i00.8658502 


\section{Introdução}

O ateliê de projeto de arquitetura configura-se como um espaço interdisciplinar, envolvendo diferentes conhecimentos para solução de problemas práticos e personalizados, dentre eles, a concepção arquitetônica e sua materialização (AGUIAR; SPENCER; FAVERO, 2018; MEDEIROS, 2014; VIDIGAL, 2010). Os saberes construídos no processo de ensino-aprendizagem dos ateliês de projeto de arquitetura se organizam em oficinas de produção experimental, práticas reflexivas, construídas pela manipulação de formas e conteúdo. A relação forma-conteúdo é mutável durante o processo de projeto de arquitetura, o que a configura como uma atividade reflexivaoperativa (OLIVEIRA, 2007) e/ou crítica-reflexiva (SCHON, 1980), tanto em sala de aula como na profissão de arquiteto e urbanista. A relação entre essas variáveis nem sempre é clara, especialmente quando se trata dos processos de ensino-aprendizagem nas escolas de arquitetura e urbanismo.

Dentre as competências e habilidades para a formação profissional do arquiteto e urbanista, o conhecimento interdisciplinar fica evidente nas disciplinas de ateliê de projeto de arquitetura. Na elaboração do projeto é necessário relacionar o aprendizado sobre as outras áreas do conhecimento para sua consolidação. Dentre essas outras áreas, destacam-se os conteúdos sobre materiais de construção, técnicas e sistemas construtivos e a compreensão de sistemas estruturais (BRASIL, 2010).

Neste contexto, o objetivo deste trabalho é compreender as necessidades, expectativas e demandas da tectônica em um ateliê de projeto de arquitetura de um curso de graduação em arquitetura e urbanismo, com proposição de solução para a demanda exposta, pela abordagem do design thinking. A pergunta que orientou esse trabalho foi: "Quais as dificuldades relacionadas às soluções técnicas nos ateliês de projeto de arquitetura?". Utilizando entrevistas, observação participante e mapa de empatia foi possível realizar uma pesquisa qualitativa com estudantes e professor.

\section{A tectônica e o ensino-aprendizagem do projeto de arquitetura}

A arquitetura foi caracterizada por Vitruvius, arquiteto romano que viveu no século I A.C., pelo trinômio Firmitas, Utilitas e Venustas. Essas palavras descrevem a solidez, a utilidade e a estética de uma edificação, e a necessidade de solução interdisciplinar na criação dos espaços arquitetônicos por meio dos projetos. A dimensão humana e a dimensão construtiva do projeto são essenciais para a materialização dos projetos criados, cujos conteúdos variam entre a arte e a técnica. A arquitetura é compreendida pelos distintos conhecimentos das ciências sociais, das tecnologias e/ou das artes. (VIDIGAL, 2010).

Para materializar um projeto de arquitetura, considera-se a concepção estrutural e a definição de aspectos construtivos, conhecidos também por tectônica (AGUIAR; SPENCER; FAVERO, 2018). A tectônica surgiu no século $18 \mathrm{com}$ a ideia de trazer os conhecimentos técnicos da construção para o projeto de arquitetura, sendo definida como "a arte da construção", "poética da construção" e "o potencial de expressão construtiva". Alguns teóricos, como Botticher na arquitetura grega, Gottfried Semper e sua teoria da combinação entre técnicas e materiais na arquitetura (pedra, argila, tijolo e madeira), Peter Collins com a proposta de tectônica como abordagem interdisciplinar, Eduard Sekler trazendo conceitos da estrutura na arte e arquitetura e Kenneth Frampton, enfatizam o termo tectônica em suas pesquisas, descrevendo-a como uma dimensão material, construtiva e tátil da arquitetura (AMARAL, 2009; ANDRADE, 2016). 
A tectônica abrange além da construção, a relação da forma da arquitetura e das artes (FRAMPTON, 1990). Resolver os aspectos técnicos do projeto de arquitetura em conformidade com as inovações tecnológicas é uma das dificuldades enfrentadas pelos arquitetos. Para estes profissionais, é imprescindível a concepção da obra arquitetônica como um todo, absorvendo os aspectos formal, técnico e funcional dos edifícios (DIEZ, 2012).

Quem cria a forma se responsabiliza por criar a estrutura e a materialização (REBELLO, 2000). A solução construtiva e a intuição estrutural devem ser ensinadas no contexto do projeto arquitetônico nas escolas de arquitetura, desenvolvendo habilidades e competências nos estudantes e futuros arquitetos (SILVA; SOUTO, 1997; DIEZ, 2012). A definição da estrutura em um projeto de arquitetura pode configurar um agente estressor do projeto, visto a importância da relação entre a estratégia projetual e a solução estrutural correspondente (AGUIAR; SPENCER; FAVERO, 2018). Em sala de aula, as dificuldades na associação entre estes dois temas estão relacionadas às habilidades dos estudantes em identificar os problemas, estruturar raciocínio lógico integrado, propor soluções com base na experiência passada, flexibilizar as ideias fixas para propor novas soluções e a falta de reflexão sobre a própria prática projetual nos ateliês de projeto de arquitetura (FLORIO, 2011).

$\mathrm{Na}$ arquitetura e urbanismo, o desenvolvimento de pensamento ativo considera o conhecimento tácito obtido pela reflexão na ação. A habilidade surge da prática por meio de solução de problemas reais, quando o problema instiga e estimula o pensamento pelas surpresas, sendo este conhecimento originado da ação para resolver as questões encontradas (SCHON, 1983). Estudos do campo da cognição indicam a percepção e o raciocínio como meios viáveis para a aquisição do conhecimento e, no caso dos projetos de arquitetura, podem ser usados pela experimentação por meio de esboços, desenhos, maquetes físicas, modelos digitais, fotos, entre outros. Desta forma, transforma-se o saber tácito em conhecimento explícito, por meio da aprendizagem das teorias da arquitetura pela prática, experimentação e relatórios de aprendizagem (FLORIO, 2011).

Estratégias de ensino-aprendizagem inovadoras têm sido discutidas atualmente, considerando o pensamento ativo dos estudantes. Dentre essas estratégias, pode-se citar a aprendizagem baseada em problemas, a aprendizagem baseada em projetos, o design thinking, a gamificação, dentre outras. Geralmente, essas metodologias inovadoras incentivam o desenvolvimento de habilidades para o século XXI, como a curiosidade, reflexão, solução de problemas, autonomia no próprio aprendizado e tomadas de decisão (CAVALCANTI; FILATRO, 2018).

O Design thinking é uma abordagem adequada para solução de vários tipos de problemas, como os relacionados aos produtos, processos, sistemas e experiências dos usuários. O pensamento do design thinking foi discutido em profundidade ao longo da história da teoria do design, por meio de estudos sobre a estrutura do processo de pensamento dos designers. A tese de doutorado de Bruce Archer, defendida no Royal College of Art (Londres) e publicada em 1968, considera no processo de design a incorporação de conhecimentos de teoria dos jogos, ciência de gerenciamento e processos de decisão de negócios (BOYD DAVIS; GRISTWOOD, 2016). Cada problema tem seu objetivo específico e o design thinking é centrado no ser humano, atendendo aos critérios da desejabilidade ou necessidades humanas, de viabilidade e de praticabilidade, com criação de soluções inovadoras (BROWN, 2010). Entendem-se como necessidades os desejos emocionais e / ou concretos das pessoas envolvidas no problema. Por meio da criatividade e de um trabalho com uma equipe colaborativa, essa abordagem leva à geração de soluções que se adaptam ao contexto real do público- 
alvo, usando métodos e processos oriundos dos projetos dos designers. A proposta gerada por meio do design thinking é "profundamente humana pela própria natureza" (CAVALCANTI; FILATRO, 2018, p.21).

Considerando as dificuldades enfrentadas pelos arquitetos e que também existem nos ateliês de projeto das escolas de arquitetura, relacionadas com a interação entre tectônica e projeto arquitetônico, ferramentas do design thinking podem ser utilizadas para auxiliar na proposta de soluções. As principais ferramentas são: (1) o HumanCentered-Design (HCD), da empresa IDEO, que considera como etapas do processo iterativo o 'ouvir-criar-entregar', incluindo a desejabilidade, praticabilidade e viabilidade nas soluções, que podem ser revisitadas continuamente visando melhorias (IDEO, 2009) e (2) o Bootcamp Bootleg, da Universidade de Stanford, que considera como principais etapas do design thinking a 'empatia-definição-ideação-prototipação-teste', intercalando momentos de pensamentos concreto e abstrato (D.SCHOOL, 2011).

Essa abordagem pode ser aplicada em quatro grandes áreas de conhecimento que estão interconectadas: (1) comunicação visual, (2) produtos e materiais, (3) atividades e organização de serviços e (4) problemas complexos e gestão de vivências, trabalho, diversão e ensino. Esta última área preocupa-se em explorar o papel do design thinking no desenvolvimento e integração de seres humanos em ambientes colaborativos (BUCHANAN, 1992).

O design thinking vem sendo estudado no campo da inovação, onde pode ser aplicado como uma metodologia para solução de problemas, como também em estratégias de ensino-aprendizagem ou como uma abordagem de inovação (BECKMAN; BARRY, 2007). O desafio é sempre criar soluções desejáveis, viáveis e praticáveis, por meio da colocação das pessoas envolvidas no processo dentro do contexto em que ocorre a situação complexa. No caso das estratégias de ensino-aprendizagem para o campo da educação, o design thinking é visto como uma abordagem pedagógica centrada no ensino colaborativo, inovador e ativo (CAVALCANTI; FILATRO, 2018).

\section{Método}

Esse trabalho ocorreu na disciplina Projeto Arquitetônico VI - (P6), da $8^{\text {a }}$ fase do curso de Arquitetura e Urbanismo na Universidade Federal de Santa Catarina, durante o semestre 2019/1. Uma das autoras participou desta disciplina na modalidade estágio em docência e, junto do professor, desenvolveu as atividades propostas pelo cronograma. A ementa da disciplina contempla o "Projeto Executivo e o Detalhamento de projetos complementares desenvolvidos no Projeto Arquitetônico V - (P5)". Trata-se da continuidade do projeto elaborado no semestre anterior, relacionado aos edifícios em altura, com maior aprofundamento e complexidade nas definições, especialmente nas soluções técnicas. Em função da variedade de propostas de projetos e escalas trabalhados no semestre anterior, a definição do escopo de trabalho individual foi realizada caso a caso.

O cronograma foi dividido em quatro etapas: (1) Revisão do anteprojeto; (2) Detalhamento dos sistemas, (3) Detalhamento da fachada e (4) Detalhamento das áreas de concentração hidrossanitárias. No início do semestre houve a apresentação de uma palestra intitulada "Estruturas para arquitetura - orientações para projeto", apresentada pela estagiária docente, que contemplou os seguintes conteúdos: (1) contenções; (2) tópicos especiais - detalhes de estruturas; (3) concepção estrutural; (4) pré-lançamento da estrutura; (5) pré-dimensionamento da estrutura; (6) balanços; (7) estabilidade global - ações horizontais do vento em edifícios verticalizados. Na revisão do anteprojeto, houve adequação de aspectos relacionados aos projetos 
complementares, bem como especificações de materiais nas plantas de todos os níveis. No detalhamento houve aprofundamento na definição estrutural, hidrossanitária, ambiental e outros aspectos. Os assessoramentos realizados tinham como intenção rever e detalhar o anteprojeto elaborado na disciplina Projeto Arquitetônico V. Ocorreram seminários colaborativos ao longo do semestre, para apresentar e debater a proposta de projeto de cada estudante com os demais colegas, bem como assessoramentos individuais e coletivos dos projetos.

Quanto às técnicas de pesquisa adotadas para coleta de dados, esse trabalho baseouse na observação direta intensiva, por meio da observação participante, da realização de entrevistas e pela aplicação do mapa de empatia conforme a abordagem do design thinking. A observação sistemática em campo foi adotada como elemento da investigação científica para identificação e registro das atitudes comportamentais observadas nos estudantes nesta experiência. As entrevistas auxiliaram no diagnóstico e identificação de sentimentos, opiniões, condutas e averiguação dos fatos (MARKONI e LAKATOS, 2003). As entrevistas foram realizadas com auxílio do aplicativo "Gravador de voz fácil", pelo dispositivo móvel, conforme registro de pesquisa aprovado no Comitê de Ética da Universidade Federal de Santa Catarina (CAAE: 13522919.6.0000.0121, Número do Parecer: 3.400.810) aprovada em 19/06/2019.

O mapa de empatia é uma ferramenta do design thinking que foi adotada para desenvolver empatia com os estudantes, a fim de compreender a realidade do ateliê de projeto de arquitetura. Todas as técnicas apresentadas nessa pesquisa preveem a imersão empática de uma das pesquisadoras na realidade dos sujeitos investigados, conforme as propostas iniciais da abordagem do design thinking.

Com base nos métodos para coleta de dados acima mencionados, essa pesquisa é classificada com uma abordagem qualitativa, conforme apresentado na Figura 1. $\mathrm{Na}$ análise de conteúdo, foi possível elaborar um brainstorming para idear uma possível solução às dificuldades identificadas no ateliê. Na sequência, foi materializada uma ideia de solução, referente à criação de uma página em ambiente virtual de aprendizagem, Moodle, contendo informações (textos, artigos, blogs, links, vídeos...) sobre os assuntos apontados como dificuldades pelos estudantes no ateliê de projeto. A ideia é aproximar os conteúdos em um único ambiente, facilitando o acesso à informação para os estudantes de arquitetura.

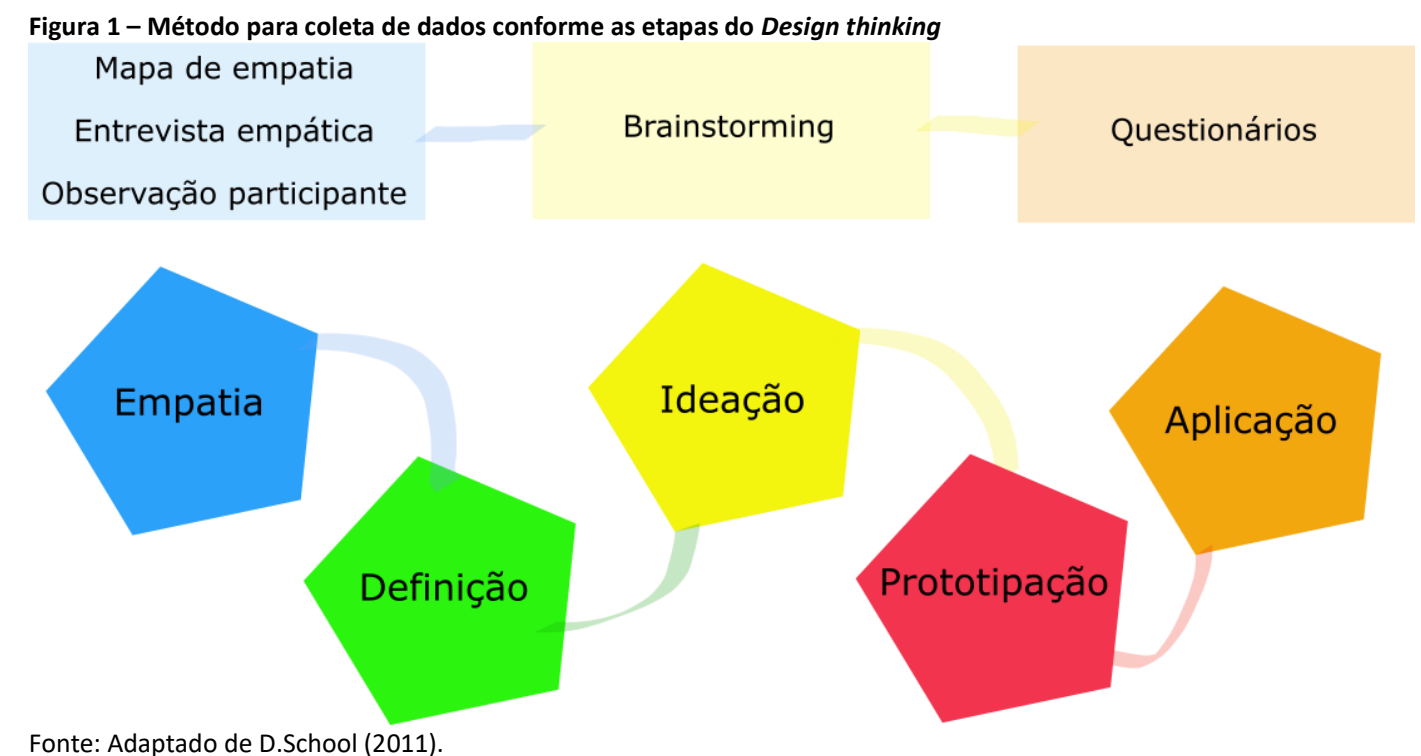




\section{Observação participante}

As aulas ocorreram entre os meses de março e julho de 2019. A turma era composta por 16 estudantes e pelo professor, mas participaram dessa pesquisa 12 estudantes e o professor da disciplina. Dentre os participantes, $54 \%$ eram do sexo masculino e $46 \%$ do sexo feminino. A maioria dos estudantes que participaram da pesquisa era da oitava fase (42\%), ou seja, do período regular dessa disciplina. Alguns estudantes eram da $9^{a}$ fase (25\%) e outros estavam a mais de cinco anos no curso, ou seja, passaram do período mínimo de conclusão do curso ( $10^{\mathrm{a}}$ fase), conforme segue: $13^{\mathrm{a}}$ fase $(17 \%), 14^{\mathrm{a}}$ fase $(8 \%)$ e $16^{\mathrm{a}}$ fase (8\%). Em relação à idade dos participantes, a maioria compreende a faixa etária dos 21-25 anos, apenas dois estudantes possuíam idade superior, um com 31 anos e outro com 53 anos, além do professor com 62 anos.

Cada estudante desenvolveu seu projeto de forma individual, com assessoramento do professor e uma das autoras, no qual levantava suas demandas, necessidades e dúvidas existentes em relação ao projeto arquitetônico em desenvolvimento. A função do assessoramento foi de orientação e direcionamento para que o estudante descobrisse e investigasse o problema. Por meio de um diário de classe, foram descritas as observações sobre os aspectos abordados por cada estudante, relativos às soluções técnicas dos projetos de arquitetura, bem como questões comportamentais. A observação participante foi realizada com o intuito de conhecer o contexto e a dinâmica dos ateliês de projeto e as relações entre professor e estudantes.

\section{Entrevistas}

Foram realizadas entrevistas individuais com cada um dos estudantes do grupo. As entrevistas ocorreram nos dias 26/06/2019, 03/07/2019 e 11/07/2019, por meio de perguntas formuladas, com uma ordem pré-estabelecida. $O$ objetivo das entrevistas foi de compreender as necessidades, expectativas e demandas dos estudantes de ateliê de projeto em Arquitetura e Urbanismo. Para isso, os estudantes responderam três blocos de perguntas, que compreendem: (1) os aspectos gerais e necessidades técnicas dos ateliês de projeto, (2) as expectativas em relação às disciplinas técnicas e à aprendizagem e (3) as demandas existentes envolvendo recursos, atividades e aprendizados (Quadro 1).

\begin{tabular}{|c|c|c|}
\hline Blocos & & Perguntas \\
\hline $\begin{array}{c}\text { 1- Aspectos Gerais } \\
\text { (Necessidades) }\end{array}$ & $\begin{array}{l}\text { a) } \\
\text { b) } \\
\text { c) } \\
\text { d) }\end{array}$ & $\begin{array}{l}\text { Quais foram suas principais dúvidas técnicas (estruturas / construção) neste projeto? } \\
\text { Quais as suas necessidades técnicas no projeto hoje? } \\
\text { O que você fez ou tem feito para sanar essas necessidades técnicas? } \\
\text { Porque surgem dúvidas técnicas no ateliê de projeto? }\end{array}$ \\
\hline $\begin{array}{l}\text { 2- Disciplinas e } \\
\text { Currículo (Expectativas) }\end{array}$ & $\begin{array}{l}\text { f) } \\
\text { g) } \\
\text { h) } \\
\text { i) } \\
\text { j) }\end{array}$ & $\begin{array}{l}\text { Como seria uma disciplina de estruturas ideal para estudantes de arquitetura e urbanismo? Quais as } \\
\text { características de uma disciplina de estruturas ideal? } \\
\text { Como melhorar seu entendimento de estruturas e construção em sala de aula? } \\
\text { Como seria o ateliê de projeto arquitetônico ideal? Quais as características de um ateliê de projeto } \\
\text { arquitetônico ideal? } \\
\text { Como as dificuldades técnicas existentes hoje poderiam ser sanadas? } \\
\text { Como seria organizado o ensino/currículo para garantir que diminuíssem as dificuldades técnicas nos } \\
\text { projetos de arquitetura? } \\
\text { Como foi a sua trajetória ao longo do curso de arquitetura? O que aprendeu sobre estruturas? }\end{array}$ \\
\hline $\begin{array}{l}\text { 3- Recursos, atividades } \\
\text { e aprendizados } \\
\text { (Demandas) }\end{array}$ & $\begin{array}{l}\text { k) } \\
\text { I) }\end{array}$ & $\begin{array}{l}\text { Que tipo de conteúdo você necessita ter para eliminar as dificuldades no desenvolvimento técnico dos } \\
\text { projetos de arquitetura nos ateliês de projeto arquitetônico? } \\
\text { Você já recebeu aulas desse conteúdo anteriormente no curso? Alguém já te deu dicas sobre isso? Você } \\
\text { poderia relacionar conteúdos que faltaram no ensino para dar suporte ao ateliê? } \\
\text { Como você imagina o ensino desses conteúdos para sanar as dificuldades existentes? } \\
\text { Como você gostaria de aprender sistemas estruturais/construtivos para uso posterior no ateliê de } \\
\text { projeto arquitetônico? } \\
\text { Em sua opinião, as inovações tecnológicas poderiam contribuir para sanar as dificuldades existentes? } \\
\text { Como? }\end{array}$ \\
\hline
\end{tabular}




\section{Mapa de empatia}

Os estudantes e o professor foram convidados a responder o mapa de empatia, conforme modelo da D.School (CAVALCANTI, 2015, p.253). Um mapa de empatia é uma ferramenta para ajudar a sintetizar as observações e extrair ideias inesperadas pelas crenças, experiências, percepções, atitudes e emoções do público-alvo. O objetivo dessa ferramenta foi identificar as características principais do público-alvo envolvido no ateliê de projeto, e mapear o que eles pensam, dizem, fazem e sentem a respeito das demandas e necessidades técnicas encontradas no ateliê de projeto arquitetônico Vl. O mapa de empatia foi aplicado nos dias 26/06/2019 e 03/07/2019.

\section{Resultados e discussões}

\section{Observação participante}

Pela observação participante, notou-se que os estudantes tinham interesse em assessorar a parte técnica dos projetos, pois em todas as aulas organizavam uma lista ordenando os assessoramentos para um atendimento individual (Figura 2). Algumas vezes, eles participavam coletivamente dos assessoramentos, discutindo temas comuns, como nos casos dos projetos elaborados com estrutura em aço. Destaca-se que em muitas oportunidades, os estudantes convidavam os demais para esclarecimentos das dúvidas comuns em seus assessoramentos individuais. Os principais temas técnicos assessorados foram a concepção estrutural (modulação, pré-lançamento e prédimensionamento), estruturas de contenção (drenagem, impermeabilizações, dimensionamento, possíveis soluções), possibilidades de soluções técnicas para o projeto, uso de estruturas em balanços, circulações verticais e Instruções Normativas do Corpo de Bombeiros.

Figura 2 - Assessoramento da concepção estrutural dos estudantes por meio do papel manteiga sobre projeto bidimensional e por meio da modelagem paramétrica
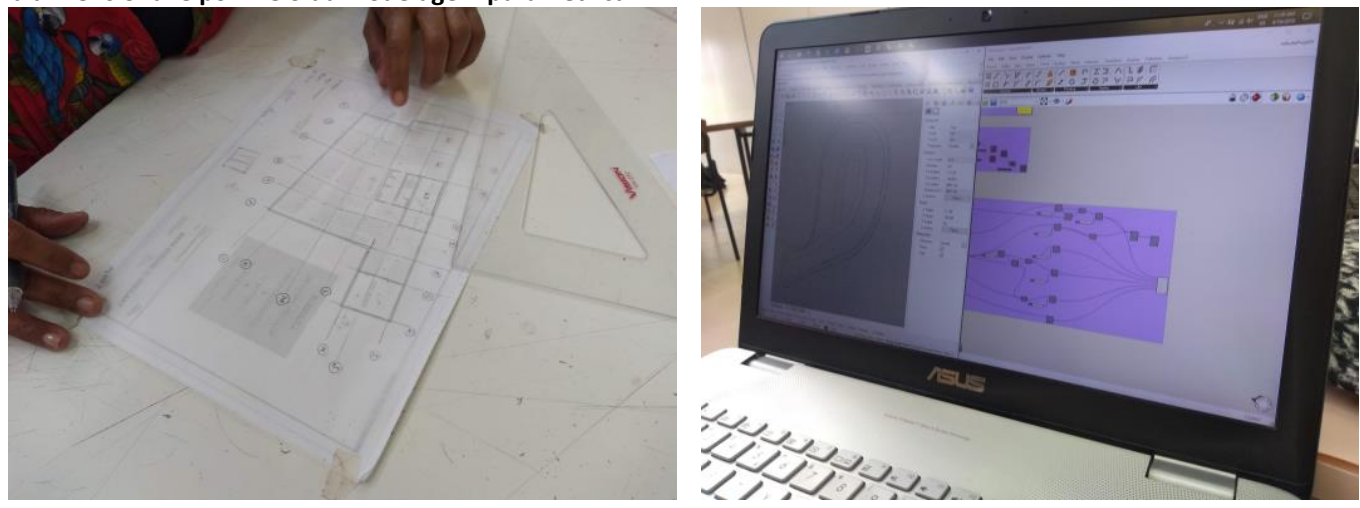

Fonte: os autores.

\section{Entrevistas}

Em relação às questões do Bloco 1 apresentadas no Quadro 1, os estudantes confirmaram que consideram importante envolver a definição técnica dentro do ateliê de projeto de arquitetura, especialmente no início do curso. Os estudantes descreveram que alguns ateliês não exigem a definição estrutural e enfatizam os layouts, plantas, fachadas, volumetria e outras soluções arquitetônicas.

As principais dúvidas técnicas destacadas foram o entendimento do tipo de estrutura para cada proposta arquitetônica, e sobre como realizar o pré-dimensionamento da estrutura e o pré-lançamento da estrutura. Neste ateliê, os estudantes contaram com a participação de uma estagiária docente formada em engenharia civil, que auxiliou nas 
orientações do professor arquiteto. Usualmente não há participação de engenheiros dentro do ateliê de projeto de arquitetura, mas a experiência apresentou um resultado positivo para o processo de ensino-aprendizagem de estruturas dentro do ateliê de arquitetura. Normalmente, os estudantes não identificam com facilidade a solução estrutural de seus projetos de arquitetura. As dúvidas surgem em horários extraclasses, quando estão desenvolvendo o projeto e refletindo sobre as decisões projetuais.

Para tentar resolver a estrutura nos projetos, alguns estudantes buscam respostas na internet ou com outro professor para orientar a questão, visto que normalmente as disciplinas de ateliê de projeto arquitetônico desta instituição se desenvolvem sem a colaboração de professores da área de engenharia. Destacam que por haver muitas soluções técnicas, as vezes acabam encontrando dificuldades na escolha das tipologias estruturais.

Em relação às questões do Bloco 2 apresentadas no Quadro 1, os estudantes sugerem que visitas em obras e integração de diferentes áreas no ateliê de projeto são formas de melhorar o ensino-aprendizagem de tecnologia no curso. Outra forma é realizar mais aulas expositivas dentro do próprio ateliê, para assuntos pontuais e necessários ao projeto arquitetônico, com exposição de exemplos e referenciais, legislação e outras observações importantes para o desenvolvimento do projeto.

Foi mencionada a importância de promover um ateliê integrado, que contemplasse estudantes de diferentes cursos trabalhando de forma colaborativa, unindo as diversas disciplinas ou adicionando mais áreas nos ateliês de projeto de arquitetura. Outros estudantes destacam a importância de relacionar a teoria com a prática e de expor os conteúdos de uma forma visual. Houve ainda uma contribuição quanto à importância dos seminários dentro do ateliê, destacando que é possível aprender com o trabalho do colega, no modelo estudante ensina estudante.

Nas entrevistas realizadas, foi realçada a falta de interdisciplinaridade entre as disciplinas de cálculo de estruturas de concreto, aço e madeira e os ateliês de projeto. $\mathrm{Na}$ visão dos estudantes, enquanto as necessidades do projeto são mais abrangentes e estão voltadas ao entendimento de soluções técnicas e possibilidades de uso no projeto de arquitetura, as disciplinas de estruturas ensinam calcular as emendas e parafusos.

Em relação ao terceiro Bloco de perguntas apresentadas no Quadro 1, uma sugestão seria abordar assuntos de tecnologia com exemplificações e simulações, para entender como ocorre o comportamento das estruturas. Os estudantes concordam que a introdução de inovações tecnológicas no ateliê ajuda a entender a proposta técnica e melhora a visualização e entendimento da complexidade do projeto. Além disso, sugerem ao professor ter um portfólio com imagens de obras que possuem as soluções técnicas necessárias e instigantes para o projeto, servindo como referencial para as propostas e ampliando o repertório com a apresentação de diferentes materiais e soluções diversas.

Uma estudante destaca que só conseguiu aprender uma questão técnica porque precisou usar no projeto de arquitetura e diz que se não precisasse dessa solução, talvez não aprendesse. Com isso, a estudante concluiu que eles têm que querer aprender ou têm que precisar daquele entendimento para adquirir o conhecimento. Conseguir fazer uma arquitetura bonita, mas que funcione, é o que faz sentido para essa estudante.

Foi comentado que é preciso ensinar o fluxo de trabalho de ateliês, considerando a documentação e métodos de projeto e foi destacada que a metodologia do ateliê ainda é muito livre e precisa de autonomia do estudante para a aprendizagem. 
Enquanto alguns estudantes destacam as dificuldades em ter autonomia no seu próprio aprendizado, outros afirmam que aprendem mais quando vão atrás das respostas para os problemas encontrados no projeto. A necessidade da pesquisa e a busca pelas soluções para os problemas ficam evidenciados nos ateliês pelos assessoramentos dos projetos, onde o estudante traz sua demanda e recebe orientação e auxílio para buscar as respostas aos problemas.

\section{Mapa de empatia}

Houve a aplicação do mapa de empatia (Figura 3) para investigar o que os estudantes do ateliê dizem, fazem, pensam e sentem em relação às dificuldades técnicas de solução no ateliê de projeto de arquitetura. Os estudantes falam uns com os outros sobre os projetos, em alguns casos reclamam de alguma situação de dificuldade vivenciada, em outros casos mostram o que projetaram para o colega e debatem soluções. Um estudante se diz preocupado com sua formação e relaciona ao sentimento de despreparo, insegurança e desmotivação. Eles afirmam que há competitividade entre os estudantes e destacam que a faculdade tem um nível de exigência elevado, mas tentam ter uma rotina de estudos e buscam feedback com os professores.

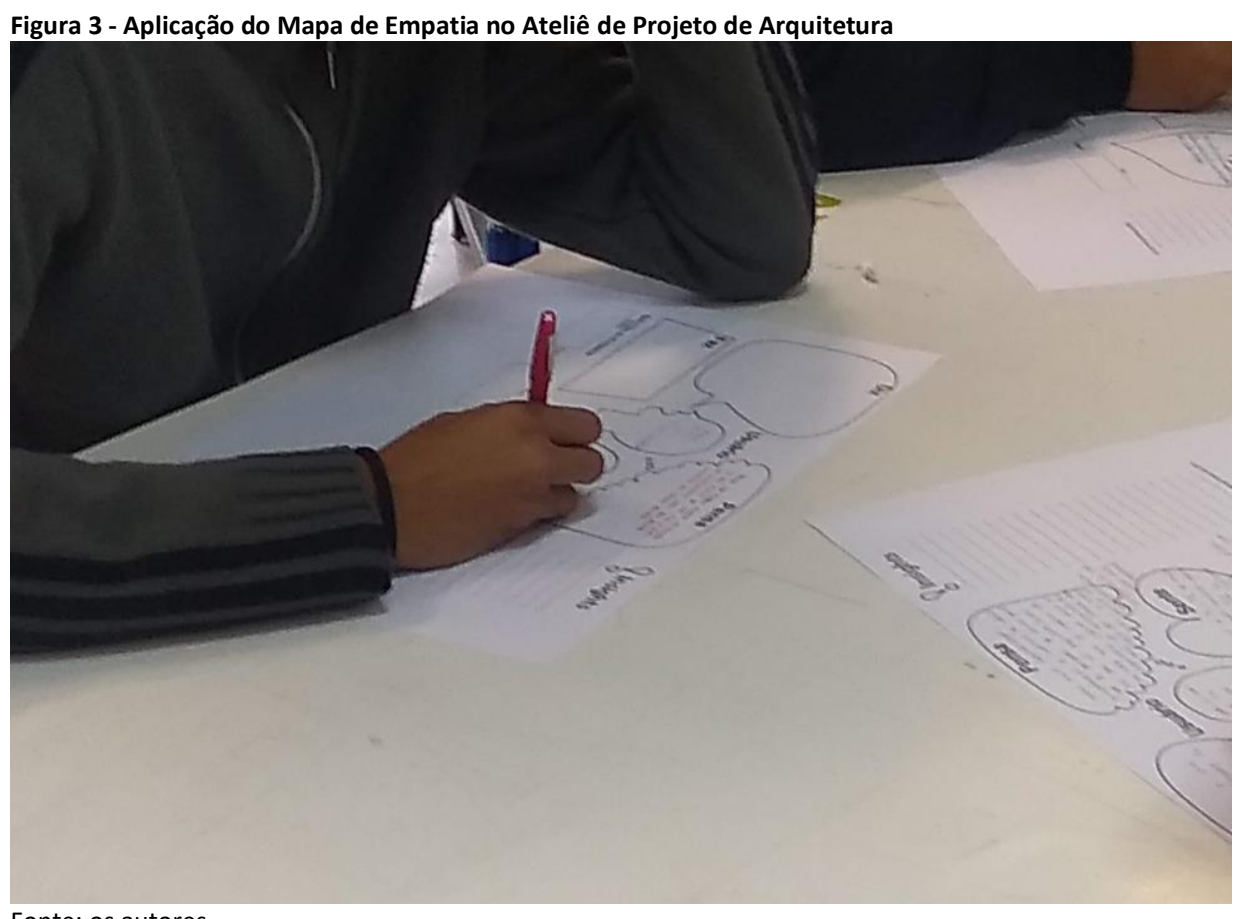

Outros estudantes lembram que não conseguem replicar os conteúdos que aprenderam nas disciplinas de cálculo nos ateliês. Um deles destaca que como o projeto nunca será viabilizado na vida real, faz o mínimo para passar. Falou-se também sobre a necessidade de integração das disciplinas e uma solução curricular, pois se faz uma inter-relação superficial das matérias técnicas no ateliê de projeto. Esse fato provoca frustração em alguns estudantes. $O$ docente destaca que tem conversado com os demais professores do departamento sobre o ateliê de projeto e informa que está em busca de integração com outras áreas do conhecimento, visto que o ateliê é um local de troca de saberes.

Uma estudante pensa que faltou aprendizado nas fases iniciais do curso, e que acabando esse projeto, ainda sente vontade de praticar mais projeto para adquirir mais segurança e mais aprendizados. Com esta observação, destaca-se a importância da integração e interrelação entre as disciplinas da grade curricular, incluindo as unidades 
do início do curso, integrando-as também com os ateliês de projeto. Os estudantes sentem um distanciamento da vida real, desmotivação e falta de foco na solução do projeto. Para eles, o ensino é muito fragmentado, as matérias de cálculo são muito abstratas e por isso se sentem frustrados e travados. Outros apontam que o curso cobra conteúdos que não são ensinados e, por isso, se sentem frustrados e ansiosos por não conseguir atingir o nível esperado pelos professores.

O docente pensa que as dificuldades relacionadas ao aprendizado técnico surgem do distanciamento entre o ensino e a aplicação simultânea em ateliê, e pensa que os estudantes não estão conseguindo relacionar e integrar os conhecimentos curriculares, o que reflete em sentimento de desestímulo. Um dos estudantes pensa que o projeto de arquitetura, ao longo do currículo, fica só em definições conceituais e, que quando chegam na disciplina Projeto Arquitetônico V e VI, se sentem perdidos por nunca terem aplicado esse conhecimento técnico anteriormente. Esse mesmo estudante pensa que ao mesmo tempo que sabe calcular um parafuso, não sabe escolher as melhores soluções para a estrutura e não se sente preparado para ser um arquiteto. Alguns estudantes destacaram o sentimento de pressão pelos melhores resultados.

A elaboração do mapa de empatia permitiu inferir algumas ideias sobre as crenças e emoções desse grupo:

1. Identificação de uma desconexão entre o que dizem e fazem quanto grupo: alguns estudantes vivenciam um ambiente competitivo dentro do ateliê e não mostram seus projetos ou não comentam sobre suas dificuldades com os colegas. Eles tentam buscar outras atividades para se manter mais motivados. Outros estudantes contam com o apoio dos colegas e dos demais docentes do departamento para suprir as demandas técnicas dos ateliês, de forma colaborativa e organizada. Percebe-se a existência de dois grupos, os estudantes que trabalham de forma mais individual e os estudantes que trabalham de forma mais colaborativa, e isso impacta na performance quanto às soluções técnicas propostas no projeto de arquitetura. $\mathrm{A}$ motivação no contexto acadêmico do curso de graduação em arquitetura e urbanismo foi objeto da pesquisa de Zanatto (2007), que informa que padrões e comportamentos negativos estão relacionados com a chamada meta performance (da relação do estudante com a obtenção de resultados e a comparação com os outros estudantes). Para este autor, a meta domínio (foco do trabalho está no aprender ou no envolvimento na tarefa) é positiva para o aprendizado destes estudantes nas práticas e políticas pedagógicas.

2. Identificação das necessidades: no geral, os estudantes e o professor destacam a importância de aplicação prática dos conhecimentos adquiridos nas aulas do currículo do curso, especialmente das disciplinas de cálculo de estruturas. Alguns pesquisadores recomendam adotar estratégias que privilegiem a observação de fenômenos e a experimentação sensorial no ensino de estruturas, priorizando a concepção estrutural de caráter mais criativo e especulativo, além do verificativo por meio de cálculos (ENEEEA, 2017). Destaca-se também a necessidade de interdisciplinaridade dentro do ateliê de projeto de arquitetura e as dificuldades de viabilizar essa questão.

3. Identificação de insights na visão do público-alvo: uma das possibilidades para minimizar as dificuldades técnicas na concepção do projeto é a integração entre disciplinas de diferentes áreas no ateliê de projeto. Florio (2011) descreve que a ausência de visão integrada do processo, da aplicação dos conhecimentos de diferentes áreas no projeto de arquitetura, implica em um entendimento parcial do problema de projeto por parte dos estudantes, prejudicando a compreensão global 
de questões estéticas, funcionais e técnico-construtivas. Outra possibilidade é alterar a dinâmica das aulas de estruturas, tornando-as menos abstratas e mais relacionadas com as demandas do projeto. A inserção da técnica nos ateliês de projeto deve iniciar desde as fases iniciais do curso, portanto, é necessária uma revisão curricular. O professor da disciplina destaca a importância da reciclagem dos docentes de projeto quanto aos conteúdos técnicos.

Essa dinâmica interdisciplinar do ateliê de projeto de arquitetura pode explicar a frustração e ansiedade que muitos estudantes sentem, e por isso reclamam, pois o ateliê não tem respostas objetivas, por isso, é necessário promover a autonomia dos estudantes para busca de respostas aos problemas práticos. O estudante de arquitetura precisa ter uma postura ativa. Não há dúvidas que a fragmentação do ensino e a falta de interdisciplinaridade curricular contribuem para potencializar as dificuldades técnicas nos ateliês de projeto de arquitetura. A Figura 4 apresenta uma síntese dos principais resultados encontrados com a aplicação das entrevistas, mapa de empatia e observação participante. Todas as informações foram importantes para permitir a ideação de uma solução com base na abordagem do design thinking.

Definição, ideação e prototipagem

Após a obtenção dos resultados por meio da observação participante, entrevistas e mapa de empatia foi realizada a análise de conteúdos pelos pesquisadores, que permitiu a definição de quais são as três principais demandas e necessidades técnicas dos estudantes de projeto de arquitetura: a) concepção estrutural (modulação, prélançamento e pré-dimensionamento); b) paredes de contenção (drenagem, impermeabilizações, dimensionamento, possíveis soluções para o desnível e o tipo de solo do projeto, técnicas construtivas e outros) e c) possibilidades de soluções técnicas para o projeto.

Após a definição, houve um brainstorming e a ideação de uma possível solução para as dificuldades encontradas no ateliê, por meio da criação de uma página em ambiente virtual de aprendizagem, conhecida como "Moodle", que permite o acesso conjunto a todos os estudantes e professores. Essa página serve como repositório das principais bibliografias (vídeos, artigos, materiais, imagens, referenciais...) sobre questões técnicas relacionadas às dificuldades apontadas pelos estudantes no ateliê de projeto. Uma vantagem deste protótipo é a possibilidade de atualização constante do conteúdo, podendo ter sugestões/indicações de conteúdos oriundos dos próprios estudantes, de forma colaborativa (Figura 5).

Essa ferramenta contribuiu também para minimizar a competição entre os estudantes, uma vez que todos têm acesso às mesmas informações e são convidados a ajudar na atualização constante da página. Por se tratar de um ambiente virtual de aprendizagem, existe a vantagem dos estudantes poderem acessar os fóruns e debater suas dificuldades técnicas com os demais, lançar perguntas e ler questões já levantadas por outros estudantes, no modelo estudante ensina estudante, pois a dúvida de um estudante pode ser a dúvida de outros.

A passividade no processo de ensino-aprendizagem pode ser superada com escolha correta de metodologias de ensino e de ferramentas de suporte a este processo. A ferramenta sugerida na Figura 5 busca envolver o estudante no seu processo de ensinoaprendizagem de forma ativa. Pode contribuir para que eles se tornem mais autônomos e comprometidos com o próprio aprendizado, em busca de conhecimento, de excelência, pesquisando e interessados nos assuntos. 
MATtANA, L.; SOUZA, J. C.; PfÜTZenREUTER, A.H.; PIMENTA, A. F. P. de S.

Interações da tectônica no ensino de projeto de arquitetura

\section{Figura 4 - Síntese dos resultados \\ Principais Dúvidas: \\ concepção da \\ estrutura, solução estrutural, \\ estruturas de contenção}

Sentem: frustração, falta de foco, insegurança, desmotivação, ansiedade, competitividade, etc.

Bloco 1: considerar parte técnica no projeto desde fases iniciais do curso, não sabem encontrar as respostas que precisam para a solução técnica, aprendem mais quando vão atrás da resposFonte: os autores.

ta que precisam.

Figura 5 - Protótipo criado por meio do processo de design thinking

\section{Observação Participante}

Fazem: tem rotina de estudo, buscam feedback, tenta integrar disciplinas, fazem o mínimo para passar

\section{Mapa de empatia}

Falam: há competitividade, reclamam,

debatem soluções.

\section{Entrevistas}

Bloco 2: sugerem mais visitas em campo/obras, maior integração entre áreas, maior relação entre a teoria

e a prática, expor alguns

conteúdos no ateliê...

\section{Comportamento:}

Interesse nos assessoramentos

da parte técnica dos projetos

Pensam: ensino é fragmentado, abstrato, não sabem escolher as soluções técnicas

Bloco 3: realizar mais exemplificações e simulações, alunos aprendem mais de forma visual, introduzir inovações tecnológicas, obter portfólio de imagens de obras e referenciais, aprender com base em problemas...

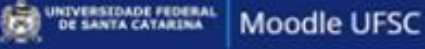

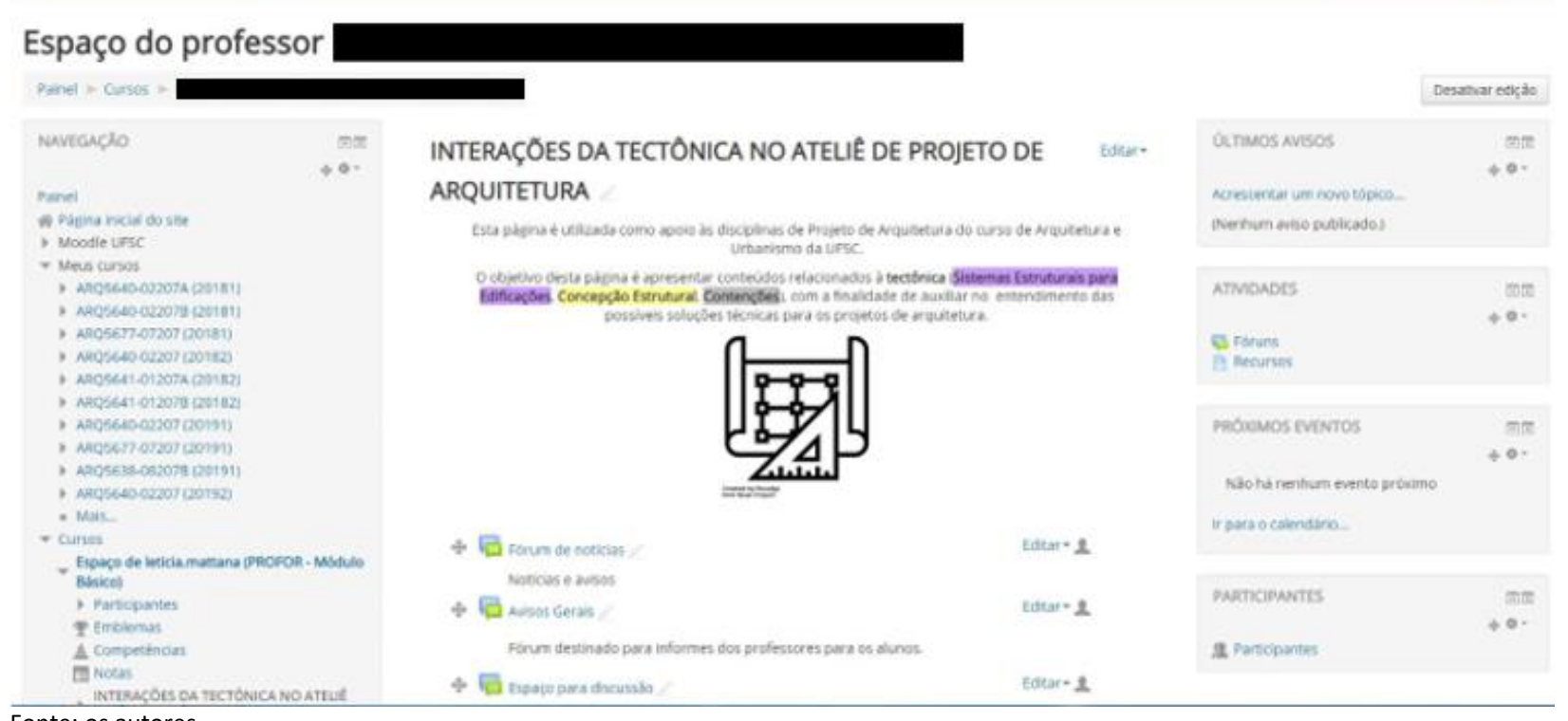
Fonte: os autores. 
Além disso, o protótipo permite que exista colaboração entre esses estudantes e também entre eles e os professores de diversas áreas, pois existe a possibilidade de utilizar os fóruns e ambientes de comunicação digital no ambiente de ensinoaprendizagem para a troca de saberes.

\section{Conclusão}

Com este estudo, puderam-se obter as principais dúvidas e dificuldades de estudantes relacionadas à tectônica no ateliê de projeto de arquitetura. Percebeu-se que os estudantes têm dificuldades em relação aos conteúdos teóricos de concepção da estrutura, de escolha da opção estrutural mais conveniente para cada caso e de definição de estruturas de contenção, quando necessárias. Destaca-se a importância de integrar docentes de diferentes áreas nos ateliês de projeto de arquitetura. A desarticulação entre o ensino de estruturas e o ensino de projeto de arquitetura existe a muito tempo, e apesar dos grandes esforços ao longo destes anos, parece que ainda hoje essa desarticulação permanece em muitas Escolas de Arquitetura, sem solução.

É necessário buscar formas efetivas de reorientar o ensino de estruturas, buscando uma formação que permita ao estudante de arquitetura formalizar soluções técnicas concretas e viáveis dentro do ateliê de projeto arquitetônico. O Núcleo Docente Estruturante desta instituição está debatendo formas de realizar os ateliês integrados com as diferentes áreas do conhecimento, contando com professores engenheiros dentro dos ateliês.

As entrevistas levantaram questionamentos que indicaram para os autores possíveis soluções para as dificuldades destacadas pelos estudantes, na maioria das vezes pequenas ações que ajudam no entendimento dos conteúdos técnicos, como por exemplo, ter um portfólio com imagens de obras que tenham as soluções técnicas e indicar bibliografias para que os estudantes possam pesquisar.

Como contribuição, foi possível idear uma solução para dar suporte à aplicação da tectônica nos projetos de arquitetura. Houve a criação de uma página em ambiente virtual de aprendizagem, que contempla conteúdos como bibliografias, imagens, vídeos e outros documentos nos temas destacados pelas dificuldades dos estudantes.

A página virtual tem como vantagem a possibilidade de acesso a qualquer hora por todos os estudantes que desejarem, além de oferecer ferramentas de comunicação para os participantes via fóruns. Além disso, ela permite que dúvidas sejam enviadas e esclarecidas a todos os participantes e que seja constantemente atualizada com novas bibliografias sobre o tema.

A solução estimula a autonomia dos estudantes na busca pelo conhecimento, incentiva o projeto colaborativo e minimiza a competitividade, promove a comunicação e compartilhamento de conhecimentos entre estudantes e professores, diminuindo as dificuldades relatadas no ateliê de projeto de arquitetura envolvendo a tectônica.

\section{Agradecimentos}

Os autores agradecem a todos os estudantes e professor que participaram ativamente das etapas descritas no método desta pesquisa. 


\section{Referências}

AGUIAR, Monica; SPENCER, Carlos Eduardo; FAVERO, Marcos. Da ideia à matéria. Uma experiência pedagógica no ensino de estruturas em ateliê integrado de projeto. Arquitextos, São Paulo, ano 18, n. 213.05, Vitruvius, fev. 2018. Disponível em: https://www.vitruvius.com.br/revistas/read/arquitextos/18.213/6900. Acesso em 15 Set. 2019

AMARAL, I. Quase tudo que você queria saber sobre tectônica, mas tinha vergonha de perguntar. Pós. Revista do Programa de Pós-Graduação em Arquitetura e Urbanismo da FAUUSP, [S. I.], n. 26, p. 148-167, 2009. DOI: https://doi.org/10.11606/issn.2317-2762.voi26p148-167.

ANDRADE, Rogério Pontes. Matrizes tectônicas da arquitetura moderna brasileira 1940 - 1960. 2016. 182 f., il. Tese (Doutorado em Arquitetura e Urbanismo) - Universidade de Brasília, Brasília, 2016. Disponível em: http://repositorio.unb.br/handle/10482/22327. Acesso em: 21 jan. 2021.

BECKMAN S.; BARRY, M. Innovation as a Learning Process: Embedding Design thinking. California Management review. v. 50, n. 1, 2007. DOI: https://doi.org/10.2307/41166415

BRASIL. Ministério da Educação. Conselho Nacional de Educação. Câmara de Educação Superior. Resolução $\mathbf{n}^{\circ} \mathbf{2}$, de 17 de Junho de 2010. Institui as Diretrizes Curriculares Nacionais do curso de graduação em Arquitetura e Urbanismo, alterando dispositivos da Resolução CNE/CES n 6/2006. Brasília, DF: Diário Oficial da União de 18/06/2010, Seção 1, pp. 37-38.

BOYD DAVIS, S.; GRISTWOOD, S. The Structure of Design Processes: ideal and reality in Bruce Archer's 1968 doctoral thesis. In: 2016 DESIGN RESEARCH SOCIETY 50TH ANNIVERSARY CONFERENCE: FUTURE-FOCUSED THINKING, 2016, Brighton. Proceedings [... ]. Brighton: University of Brighton, DRS, 2016, p. 27-30

BROWN, T. Design thinking: uma metodologia poderosa para decretar o fim das velhas ideias. 249p. Rio de Janeiro: Elsevier, 2010.

BUCHANAN, Richard. Wicked Problems in Design thinking. Design Issues, Cambridge - The MIT Press, v. 8, n. 2, p. 521, 1992. DOI: https://doi.org/10.2307/1511637

CAVALCANTI, C. C.; FILATRO, A. Design thinking na educação presencial, a distância e corporativa. São Paulo: Saraiva, 2016.

CAVALCANTI, Carolina Magalhães Costa. Contribuições do Desing Thinking para concepção de interfaces de ambientes virtuais de aprendizagem centradas no ser humano. 2015. Tese (Doutorado em Educação) - Faculdade de Educação, Universidade de São Paulo, São Paulo, 2015. DOI: https://doi.org/10.11606/T.48.2015.tde-17092015135404

DIEZ, Gloria. Projeto Estrutural na arquitetura. Porto Alegre: Masquatro e Nobuko, 2012.

D.SCHOOL. Bootcamp Bootleg. Hasso Plattner, Institute of design at Stanford, Palo-alto, p.1-44, 2011. Disponível em: https://dschool.stanford.edu/resources/the-bootcamp-bootleg. Acesso em: 13 Set. 2019

ENEEEA - ENCONTRO NACIONAL DE ENSINO DE ESTRUTURAS EM ESCOLAS DE ARQUITETURA, 3., 2017 , Ouro Preto. Anais [... ]. Ouro Preto: Editora da UFOP, 2017, p. 7-15

FLORIO, Wilson. Análise do processo de projeto sob a teoria cognitiva: sete dificuldades no atelier. Arquitetura Revista. São Leopoldo, v.7, n.2, p.161-171, 2011. DOI: https://doi.org/10.4013/arq.2011.72.06

FRAMPTON, Kenneth. Rappel à l'ordre: the case for the tectonic. Architecture Design. v. 60, n. 3-4, p.19-25, 1990.

IDEO. HCD - Human Centered Design: Kit de ferramentas. EUA: IDEO, 2009. 102 p. Disponível em: https://www.ideo.com/post/design-kit. Acesso em: Nov. de 2019 
MAtTANA, L.; SOUZA, J. C.; PFÜTZenReUTeR, A.H.; PIMENTA, A. F. P. de S.

Interações da tectônica no ensino de projeto de arquitetura

MEDEIROS, Renato. Ensino de Arquitetura, o conteúdo tecnológico e a contribuição da abordagem tectônica para o ensino de projeto. In: ENCONTRO DA ASSOCIAÇÃO NACIONAL DE PESQUISA E PÓS-GRADUAÇÃ̃O EM

ARQUITETURA E URBANISMO, 3., São Paulo, SP. Anais [...], São Paulo: ANPARQ, 2014.

OLIVEIRA, Rogério de Castro. Teoria e didática do projeto arquitetônico: uma relação permanente. Arquitetura Revista. São Leopoldo, v.3, n.1, p.57-62. ISSN 1808-5741, 2007.

REBELLO, Yopanan C. P. A concepção estrutural e a arquitetura. São Paulo: Zigurate, 2000.

SILVA, Daiçon Maciel da; SOUTO, André Kraemer. Estruturas: uma abordagem arquitetônica. Porto Alegre: SagraLuzzatto, 1997.

SCHON, Donald A. The reflective Practitioner: how professional think in action. United States of America: Basic Books, 1983.

VIDIGAL, Emerson José. Ensino de projeto arquitetônico: um estudo sobre as práticas didáticas no curso de arquitetura e urbanismo da Universidade Federal do Paraná. 2010. 330p.Tese (Doutorado) - Faculdade de Arquitetura e Urbanismo, Universidade de São Paulo, São Paulo, 2010. DOI: https://doi.org/10.11606/T.16.2010.tde18012011-111136. Acesso em: 2021-01-22.

ZANATTO, Rinaldo. Perfil Motivacional de Alunos de Arquitetura: um estudo exploratório. 2007. 132f. Dissertação (Mestrado em Educação) - Universidade Estadual de Londrina, Londrina, 2007. Disponível em:

http://www.bibliotecadigital.uel.br/document/?code=vtls000124869. Acesso em: 21 jan. 2021.

\section{${ }^{1}$ Leticia Mattana}

Engenheira Civil. Mestrado em Arquitetura e Urbanismo pela Universidade Federal de Santa Catarina. Doutorado em andamento em Arquitetura e Urbanismo pela Universidade Federal de Santa Catarina. Professora Assistente na Universidade Federal de Santa Catarina, Centro Tecnológico, Departamento de Arquitetura e Urbanismo. Endereço postal: Departamento de Arquitetura e Urbanismo, Centro Tecnológico, Campus Trindade, Universidade Federal de Santa Catarina, Florianópolis, Santa Catarina - Brasil, CEP 88040-970

\section{João Carlos Souza}

Engenheiro Civil. Doutorado em Engenharia de Produção pela Universidade Federal de Santa Catarina, Professor Titular na Universidade Federal de Santa Catarina, Centro Tecnológico, Departamento de Arquitetura e Urbanismo. Endereço postal: Departamento de Arquitetura e Urbanismo, Centro Tecnológico, Campus Trindade, Universidade Federal de Santa Catarina, Florianópolis, Santa Catarina - Brasil, CEP 88040-970

\section{${ }^{3}$ Andréa Holz Pfützenreuter}

Arquiteta e Urbanista. Doutorado em Arquitetura e Urbanismo pela Universidade Presbiteriana Mackenzie. Professora na Universidade Federal de Santa Catarina, Departamento de Engenharias da Mobilidade. Endereço postal: Rua Doutor João Colin, 2700, Joinville, Santa Catarina - Brasil, CEP 89218-000

\section{${ }^{4}$ Anna Freitas Portela de Souza Pimenta}

Arquiteta e Urbanista. Mestrado em Engenharia Civil pela Universidade Federal de Santa Catarina. Doutorado em andamento em Arquitetura e Urbanismo pela Universidade Federal de Santa Catarina. Professora Assistente na Universidade Federal de Santa Catarina, Centro Tecnológico, Departamento de Arquitetura e Urbanismo. Endereço postal: Departamento de Arquitetura e Urbanismo, Centro Tecnológico, Campus Trindade, Universidade Federal de Santa Catarina, Florianópolis, Santa Catarina - Brasil, CEP 88040-970 